\title{
Proyectos Urbanos Estratégicos para Valparaíso: una Experiencia Académica
}

\section{Valparaiso Strategic Urban Projects: An Academic Experience}

\author{
Eliana Muga Weippert ${ }^{1}$
}

Paz Carreño Zunino ${ }^{2}$

Recibido: 15 de abril de 2016

Aceptado: 23 de diciembre de 2016

\section{Resumen}

El presente artículo expone una experiencia académica del Taller de Arquitectura orientada al diseño urbano a través del desarrollo de Proyectos Urbanos Estratégicos en quebradas, donde el tema es la ordenación del territorio, sobre la base de la puesta en valor del patrimonio local (comprender y actuar en relación con la cultura local y vocación de estos territorios) con miras a alcanzar un desarrollo sustentable para los cerros en Valparaíso, Chile. La relevancia práctica es revertir los procesos de marginalidad, asociados con diversos problemas ambientales como microbasurales, ocupación ilegal de terrenos y peligro de incendios, a través de la generación de nuevas centralidades urbanas y el cuidado de las quebradas con su ocupación y manejo.

Palabras clave: estrategia urbana, nueva centralidad urbana, patrimonio cultural, proyecto urbano estratégico, quebradas.

\begin{abstract}
This paper presents the academic experience of an architecture workshop oriented towards urban design through the development of Urban Strategic Projects in ravines, where the issue is spatial planning, based on the valorization of local heritage (understanding and acting in relation to local culture and vocation of these territories) to achieve sustainable development for the hills in Valparaiso, Chile. The practical relevance is to reverse the process of marginalization associated with various environmental problems (micro-landfills, illegal occupation of land and fire hazard, among others), creating new urban centers and handling ravines with new uses.
\end{abstract}

Keywords: cultural heritage, new urban centralities, ravines, urban strategy, urban strategic projects.

\footnotetext{
${ }^{1}$ Escuela de Arquitectura Universidad de Valparaíso, Chile, Arquitecta UV, Dr(c) Urbanismo TU Delft, Holanda, Magíster DU PUC de Chile. Contacto: eliana.muga@uv.cl

${ }^{2}$ Escuela de Arquitectura Universidad de Valparaíso, Chile. Arquitecta y Magíster AHMA PUC de Chile. Contacto: paz.carreno@uv.cl
} 


\section{Introducción}

Hoy nos encontramos en un escenario donde las aceleradas transformaciones urbanas han traído como efecto mutaciones sociales, físicas y ambientales, alterando tanto el paisaje como la cultura local. Estos fenómenos acarrean problemas de segregación social, conflictos de accesibilidad a los servicios urbanos, ineficientes sistemas de movilidad, desconexión y/o carencia de las redes de infraestructura urbana en nuevas áreas residenciales, agudizándose los problemas medioambientales, sin considerar los fenómenos naturales como parte de los sistemas urbanos.

La ciudad-puerto de Valparaíso no está ausente de estos problemas. La conurbación de Valparaíso, Viña del Mar, Quilpué y Villa Alemana, posee la mayor cantidad de tomas ${ }^{3}$ de terrenos a nivel nacional. Estos "campamentos" se concentran en general en las quebradas y sectores altos de las ciudades de Valparaíso y Viña del Mar, donde "un $28 \%$ de ellos se localiza en zonas donde no se permite el uso habitacional por estar catalogadas como zona de riesgo o por estar destinadas a equipamiento, actividades productivas, entre otras" (Ministerio de Vivienda y Urbanismo, Minvu, (2013). La topografía variable de Valparaíso impulsó el desarrollo de la ciudad en el siglo XIX e inicios del siglo XX como una urbe de características especiales, declarada Ciudad Patrimonial de la Humanidad por la Unesco en 2003. La evolución de esta ciudad no ha incorporado apropiadamente las dinámicas naturales de las quebradas en relación con el desarrollo de las periferias, generándose áreas afectadas por incendios y marginalidad.

Este artículo trata acerca de la propuesta urbana e investigación asociada a esta, que busca mejorar la ocupación en la zona intermedia y alta de los cerros, particularmente en las quebradas. Estos cauces espaciales son las áreas de mayor vulnerabilidad tanto en aspectos medioambientales como sociales, carentes de lugares centrales e infraestructura adecuada, producto del crecimiento histórico; con deficiente planificación y donde se observan problemas como la ocupación ilegal de terrenos, microbasurales, pérdida de flora nativa y biodiversidad.

Se proponen Proyectos Urbanos Estratégicos (PUE), esto es, acciones puntuales en este territorio, a través de los que se busca potenciar las estructuras sociales (integrar las redes de la microeconomía local y rescatar el paisaje natural existente en el sector), incorporándolas a la nueva estructura de servicio ambiental y urbano. Estos PUE se inscriben en un Plan General que plantea fortalecer una estrategia de ciudad, donde la visión de futuro es la puesta en valor del patrimonio local (la cultura local y vocación de estos territorios) con miras a alcanzar un desarrollo sustentable para Valparaíso.

${ }^{3}$ Ocupaciones informales de terrenos. 
El análisis urbano local de Valparaíso busca identificar los valores locales, culturales y territoriales de mediana y gran escala, de modo de generar programas latentes en cruces de calles estratégicas de la ciudad, con el objetivo de desarrollar el tejido social y el intercambio económico, atraer fuentes de ingresos, mejorar las comunicaciones internas, aumentar la plusvalía del sector y mejorar la calidad de vida para sus habitantes. Así, se pretende orientar el proceso hacia un escenario futuro donde las quebradas dejen de ser espacios residuales, para pasar a ser los nuevos lugares de infraestructura de servicios ambientales, con nuevas centralidades que van tejiendo las tramas inconclusas de la ciudad, incorporando la estructura verde de las quebradas como un valor de identidad urbana, entre los otros valores urbanos existentes.

La metodología se desarrolla en el contexto académico de un Taller de Arquitectura de cuarto año de esta carrera, en el cual se han propuesto diversos equipamientos de uso público. Estos se ubican en encuentros entre avenidas conectoras horizontales (Avenida de Borde Mar, Av. Alemania, la proyectada Av. del Agua y Camino La Pólvora) y transversales ubicadas en las quebradas, cuyas propuestas son:

- Estación de Bomberos y Control Ambiental,

- Parque del Agua en la quebrada,

- Parque Urbano Cultural, Parque Centro de Exploración de Flora Nativa,

- Centro Cultural Educacional,

- Centro de Apoyo a la Infancia,

- Escuela y Facultad Universitaria Patrimonial.

\section{Breve contexto urbano territorial de Valparaíso}

La ciudad de Valparaíso se impulsó como el principal puerto de la zona central de Chile desde la construcción del ferrocarril en 1863 (Hidalgo et al., 2016) en estrecha vinculación económica con la capital del país, Santiago. Su localización, la profundidad de sus aguas marinas y la presencia constante de agua dulce, junto con su condición de anfiteatro, la hacen poseedora de cualidades naturales excepcionales.

A fines del siglo XIX e inicios del XX tuvo su máximo apogeo económico, época en donde se conformó lo que es hoy el área patrimonial. La ciudad se desarrolló principalmente en un área comercial-residencial de borde mar en la planicie triangular llamada plan - parte de esta ganada al mar- y en los cerros de carácter residencial, vinculados a través de vías en las quebradas. Estas últimas fueron urbanizadas hasta la cota $100 \mathrm{msnm}$ (Av. Alemania).

En ese período se estructuran vías principales que persisten hasta hoy, donde destacan calles paralelas al mar en el plan (Av. Errázuriz y Colón) y los cerros (Av. Alemania en cota $+100 \mathrm{msnm}$ ) en intersección de calles perpendiculares 
vinculadas con las quebradas. Sobre esta cota la ciudad se expande sin planificación, ocupando las cimas de los cerros y dejando las quebradas sin ocupación.

El terremoto de 1906 y la necesidad de espacio para la expansión urbana, generó que parte de la elite fuera trasladándose a la nueva y contigua ciudad de Viña del Mar, la cual se fue transformando en la capital turística de Chile. Durante el siglo XX, el desarrollo de ambas ciudades como conjunto y el crecimiento poblacional formaron una conurbación que hoy posee aproximadamente 1 millón de personas, y de la cual Valparaíso sigue siendo la capital administrativa, cuyas actividades económicas se centran en el comercio, turismo y servicios.

Junto con ser un puerto de importancia nacional y capital regional con su multiplicidad de servicios, es residencia del Congreso Nacional, una de las ciudades chilenas con mayor cantidad de universidades y posee un área de protección patrimonial declarada por la Unesco, presentando una rica mixtura de usos. A pesar de ello, se ha empobrecido y posee uno de los más altos porcentajes de cesantía del país, debido inicialmente a la apertura del canal de Panamá, al traslado de las sedes centrales de empresas y bancos a Santiago; y en menor medida en las últimas décadas al cese de la industria, a la tecnificación del puerto, y a las migraciones de clases profesionales y acomodadas a otras comunas de la conurbación Viña del Mar-Quilpué-Concón, entre otros motivos.

El desarrollo urbano actual de Valparaíso se ha extendido en todo el suelo habitable vinculado al plan, pues es en este donde se concentran los servicios. La ocupación de los cerros desde la cota 100 msnm, de carácter residencial, corresponde en su mayoría a grupos sociales medios y bajos.

Desde una perspectiva medioambiental, Valparaíso es parte de un corredor biológico, al encontrarse tangente a un área de Reserva de la Biósfera compuesta por los sectores de Cerro La Campana y Lago Peñuelas, territorio que pertenece al clima mediterráneo, declarada como hotspot por su gran riqueza de flora y fauna única (Moreira-Muñoz y Borsdorf, 2014). Esta característica se presenta como una potencialidad, ya que las quebradas de la ciudad y sus aguas intermitentes se conectan a este espacio territorial. Por esto Valparaíso se localiza en el punto de relación del hotspot de la $\mathrm{V}$ Región con su borde mar, por tanto en una condición ecológica privilegiada.

Valparaíso ha sido históricamente afectada por terremotos e incendios. Parte importante de estos últimos siniestros han surgido en los cerros, en el borde de los barrios marginales y bosques (de pinos y eucaliptus) de propiedad privada. En estos casos, las quebradas han servido de cauces naturales para la propagación del fuego, "con atención a las condiciones abruptas de las quebradas, aceleradoras de los incendios forestales" (Plataforma Urbana, 
2016), tal como se evidenció a gran escala en el incendio de 2014. Se observa que los temas medioambientales y paisajísticos apenas han sido considerados hasta ahora, al igual que en gran parte de las áreas urbanas chilenas, debido a la timidez de esta temática en los instrumentos de planificación (MoreiraMuñoz y Borsdorf, 2014).

La bahía de Valparaíso poseía una alta humedad original gracias a la vegetación nativa, lo cual aseguraba agua dulce constante en las quebradas porteñas. Esta condición ha sido tan profundamente modificada debido a la construcción y la introducción de especies foráneas, por lo que hoy la presencia de agua se ha reducido drásticamente y ha aumentado considerablemente el riesgo de incendio, ya que las condiciones ideales para estos son de $30 \%$ de humedad ambiental, $30^{\circ} \mathrm{C}$ y vientos de $30 \mathrm{~km} / \mathrm{hr}$.

Esta situación genera un problema latente durante todo el año, al cual se aplican medidas de corto y mediano plazo. Las primeras tienen relación con el mejoramiento de la respuesta de bomberos, organizaciones locales y otros, llevados a cabo por el Municipio y por el Gobierno Central luego del gran incendio ocurrido en 2014. Las medidas de mediano plazo, en tanto, se asocian a la inversión por parte del Estado en infraestructura clave para la ciudad, la cual se implementaría en los próximos cuatro años, y surge como política nacional ese mismo año (Ministerio del Interior de Chile, 2014).

\section{Las quebradas como potencial de recreación urbana}

Reconocer el rol ecológico y la importancia de las quebradas como cuencas urbanas-ecológicas, constituye hoy el potencial para la recreación urbana. Es en estas donde el cauce pluvial contribuye a la inclusión de áreas verdes e integración de la ciudad a la naturaleza. Es allí donde se emplazan las apropiaciones socioespaciales (minieconomías, apropiación de la pendiente, relaciones sociales vecinales) (Pino, 2015), y donde aún subsisten los paisajes fortuitos y a menudo ecológicamente diversos, fruto de la actuación de las fuerzas urbanas y naturales.

Es en estas áreas donde se concentran serios problemas urbanos ambientales, ya que estos junto a la topografía y el desarrollo urbano sobre la cota 100 msnm, han sido los responsables de la fracturación del tejido urbano/territorial, generando discontinuidad en la conectividad y las relaciones sociales entre cerros. Se observa en muchas áreas de cerros superiores de Valparaíso, tal como señala Gilberts (1994, en Lombardi, 2014), el desarrollo de áreas informales en ciudades de América Latina sobre la base del esfuerzo colectivo de mejorar las viviendas individuales, lo cual se ha transformado en asentamientos consolidados (Ascensao, 2016; Dovey, 2012).

Esta visión urbano-ecológica es fundamental en la concepción del territorio, en los estudios, investigaciones y proyectos desarrollados de la Facultad de 
Arquitectura de la Universidad de Valparaíso (UV) desde hace una década. En el ámbito académico, en los Taller de Arquitectura en la línea del territorio en 40 y $5^{\circ}$ año (Muga y Rivas, 2009), y en el ámbito profesional, como es el caso del "Pre diseño hidráulico ambiental para la Quebrada San Francisco en Valparaíso" (concurso público llamado por la Subdere, V Región en 2006), donde los profesores de la Escuela de Graduados de la Facultad de Arquitectura hacen la primera Propuesta de Parque Metropolitano para esta quebrada (Murtinho-Braga, 2007). Esta última propuesta cumple sus expectativas hidráulicas, ambientales y urbanísticas y, al mismo tiempo, sugiere el desarrollo de un equipamiento complementario.

Esta temática está comenzando a ser incluida en la actualidad en el proyecto Parque Metropolitano El Pajonal, en Cerro Monjas, Valparaíso, cuyo mandante es el Ministerio de Vivienda y Urbanismo, Minvu.

Todas estas iniciativas apuntan a la recuperación de las quebradas en diferentes enfoques. La propuesta del Taller de Arquitectura de la UV que se presenta en este artículo, inicia la transformación de las áreas de intervención y la renovación de la ciudad de Valparaíso en general, a través de intervenciones puntuales (PUE).

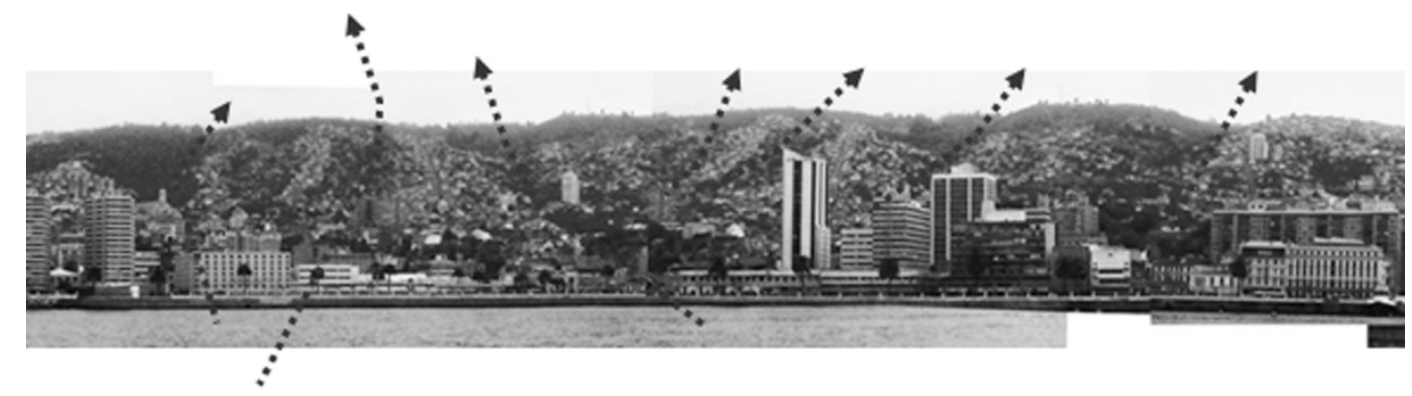

Figura 1. Vista de las quebradas de Valparaíso desde el mar.

Fuente: Elaboración propia.

Hipótesis de trabajo. Es en las quebradas donde se encuentra la oportunidad de re-crear e impulsar el desarrollo, sobre la base de la puesta en valor del patrimonio local (comprender y actuar en relación a la cultura local y vocación de estos territorios) con miras a alcanzar un desarrollo sustentable para los cerros.

\section{Marco teórico}

El comportamiento de la ciudad actual se asemeja a un sistema complejo, que participa de las características de un ecosistema, de competencias como de apoyo mutuo, en función del sistema social que lo soporta, donde los procesos de decisión se vinculan con relaciones entre el sector público - que vela por el derecho colectivo- y el conjunto de intereses individuales. Esta complejidad 
del sistema urbano es su característica más positiva y plantea un nuevo desafío al urbanista: considerarla como un aliado e incluso un objetivo (Huchzermeyer y Misselwitz, 2016), aun cuando va ligada a la idea de incertidumbre y azar. El enfoque sistémico (Fernández Güell, 1997) persigue resolver los grandes desequilibrios generados por el proceso de urbanización, a través de una organización de los sistemas de actividades urbanas, la conservación y gestión de los recursos naturales y la mejora de la calidad de vida.

De este modo, la arquitectura se vuelve a unir con el urbanismo, entendiendo el Proyecto Urbano Estratégico (PUE) como la intervención sobre la estructura organizacional de la ciudad. El proyecto urbano estratégico es un proyecto de arquitectura, que se ocupa tanto del diseño de la obra de arquitectura como del diseño del espacio público, y su rol es integrar la complejidad del sistema urbano (organización política, económica, social, ambiental), y su emplazamiento es estratégico en la medida que genere las transformaciones necesarias en busca de una visión del desarrollo sustentable del sistema urbano. El PUE es la nueva herramienta de la planificación urbana que orienta el desarrollo en busca de una mejor calidad de vida para sus ciudadanos, lo que en el largo y mediano plazo debiera traducirse en resiliencia del sistema urbano a través de la interrelación de los siguientes factores: equidad, sustentable y eficacia.

El marco conceptual y proyectual de cómo diseñar cada PUE se fundamenta en los valores locales (Hough, 2004) y territoriales (McHarg, 2000), que son los que configuran el paisaje cultural que aporta identidad a la comunidad. Esto pone en valor al paisaje natural urbano. Conjuntamente, se consideró la teoría central de Ian L. McHarg: "La ecología debe estar en el fundamento de las artes que proyectan el ambiente, comprender los procesos que configuran los paisajes y utilizarlos como fundamento del proyecto" (McHarg, 2000). De esta forma, es necesario entender la ciudad como una forma derivada de la evolución geológica y biológica, que ha sido adaptada por el hombre del desarrollo urbano, como una sucesión de adaptaciones culturales reflejadas en el plano de la ciudad y en los edificios (morfología). Las buenas adaptaciones perduran y entran en el inventario de valores. Producto de este reflejo de la apropiación del territorio en la historia es que nos encontramos con diversas unidades de paisaje en la ciudad (Massey, 2013).

En el marco de la planificación estratégica urbana (Fernández Güell, 1997), se siguió la estrategia alternativa de diseño urbano ecológico propuesta por Hough, que incluye los procesos naturales (agua, plantas, fauna, agricultura, clima), como principios de diseño, entendidos como dinámicos y presentes tanto en el paisaje urbano como el rural. Por lo cual, la ecología de recursos es el principio del mínimo esfuerzo: con un mínimo de energía se pueden maximizar los beneficios medioambientales, económicos y sociales (Revi et al., 2014). Para Hough, la idea principal del diseño urbano ecológico es entender la 
importancia del agua en los procesos naturales urbanos. El ciclo hídrico y la preservación del agua son fundamentales en el mantenimiento de la vida.

Así mismo, desde los años 60 se viene desarrollando la idea de que los corredores ecológicos representan oportunidades de conservación de la biodiversidad en regiones con escasa cobertura de áreas protegidas, zonas de extracción exhaustiva de recursos naturales o en territorios alejados de centros urbanos y políticos. Bajo la figura del corredor ecológico, se pretende conectar parques nacionales y reservas ecológicas para crear iniciativas regionales y supranacionales de conservación (Tjallingii, 2007). Con ello, se busca fomentar el desarrollo sustentable (ambiental/natural, cultural/social y productivo/económico).

Paradójicamente, las primeras iniciativas de conservación de la biodiversidad aparecen de la mano de propuestas contemporáneas de industrialización y expansión de mercados en América Latina, tales como el Tratado de Libre Comercio de las Américas-ALCA a nivel continental, el Plan Puebla Panamá-PPP en Mesoamérica y el plan de Integración de la Infraestructura Regional para América del Sur-IIRSA (Minvu, 1999). En este contexto las implicaciones políticas y económicas de la conservación se tornan polémicas. Más allá de esto, los corredores ecológicos representan una oportunidad para aplicar los principios de la equidad social (de género, edad, etnia, región y condición económica) a las políticas de conservación y a la planificación de las políticas públicas.

Hoy se entiende que un corredor ecológico debería constituirse en un espacio de continuidad natural y social para beneficio, uso y usufructo de una amplia diversidad de pobladores locales. Su espacio político debe formar parte de un modelo civilizatorio latinoamericano donde los recursos naturales aparezcan como estrategia de vida, continuidad y fuente de desarrollo social.

Sobre la base de la idea de los corredores ecológicos, la infraestructura verde en áreas urbanas pretende generar una red interconectada de espacios verdes (públicos y/o privados) donde se preservan las cualidades ambientales y de vida del medio natural en el espacio urbano, periurbano y rural. Esta red verde (de parques metropolitanos) aporta nuevas oportunidades para el desarrollo y habitabilidad, tales como actividades integradas al ecosistema, configuración de un paisaje urbano natural, aumento de plusvalía del suelo y mejoramiento de la calidad de vida de los habitantes (Simon et al., 2016). Se busca así entregar un amplio rango de servicios ambientales como "conservación de la biodiversidad, mejoras a la salud humana, hábitat para vida silvestre, modificación del clima, beneficios recreacionales, control de la contaminación, educación e investigación" (Escobedo et al., 2008, citado en De La Maza y Rodríguez, 2015). 
Los procesos de sustentabilidad de la vida deben hacerse visibles en las ciudades para fomentar la toma de conciencia acerca de su valor: parte importante de la población local ignora los procesos naturales que facilitan la disponibilidad de agua y recursos orgánicos, entre otros (Gauzin-Müller, 2002). Por lo tanto, la educación medioambiental debe potenciarse en el hogar y en los centros educativos.

Otro principio de diseño ecológico que orienta los PUE ha sido el celebrar la diversidad de habitantes, de actividades, de usos del espacio público, así como su densidad (Rogers, 2000), y conjuntamente, incorporar la riqueza del tejido social existente en la ciudad, ya que "la infraestructura (visible e invisible, grande y prosaica) está implicada en la experiencia humana de la ciudad y en dar forma a identidades sociales" (Tonkiss, 2013, citado en Amin, 2014).

Con miras a proponer un desarrollo viable para las quebradas en Valparaíso, en un contexto de equidad y sostenibilidad, este trabajo indaga acerca de esta realidad, propone nuevos escenarios orientados al respeto de los valores de construcción de identidad local, del patrimonio cultural como de la sustentabilidad del sistema, considerando tres factores que apuntan a vincularse de forma equitativa: su dimensión social, histórica y espacial/natural; factores que constituyen una parte vital del giro espacial y de la especialización de los estudios urbanos (Sojas, 2000). La herramienta es el PUE, entendido como proyecto de diseño arquitectónico y urbano, basado en conceptos ecológicos y enfocado al diseño sustentable, asumiendo la tarea con responsabilidad, de acuerdo con los principios establecidos en la Comisión Brundtland "enfrentarse a las necesidades del presente, sin comprometer a las futuras generaciones de enfrentarse a las suyas" (Unión Internacional para la Conservación de la Naturaleza, UICN, 2015).

Objetivos. Se trabaja sobre la hipótesis de que las quebradas constituyen espacios de oportunidad de desarrollo sustentable y reestructuración de la ciudad. Pero esta nueva infraestructura verde en las quebradas es mucho más que el emplazamiento de una red de espacios públicos verdes interconectados, ya que prestan servicios ambientales y urbanos a toda la ciudad y configuran el paisaje cultural. Así, se alcanzaría el arraigo en el territorio y la participación de los habitantes locales en el desarrollo sustentable del sistema urbano de Valparaíso. Se busca que la transformación de la ciudad se inicie en una acción local: el proyecto urbano estratégico es de carácter multiescalar y forma parte del sistema ecológico en sus múltiples escalas, del sistema económico/portuario regional y corredor turístico/social de este gran sistema transversal del país.

Objetivo principal. El estudio busca identificar los elementos del paisaje cultural (patrimonio urbano configurado por valores tangibles e intangibles), ofreciendo una oportunidad para el desarrollo de innovación cultural en quebradas y recuperar estos lugares de preservación del medio 
natural, dando lugar a las diversas habitabilidades latentes y múltiples actividades presentes en precariedad, orientando el desarrollo hacia la sustentabilidad de la ciudad.

Objetivos específicos. Proponer y diseñar PUE que permitan ir configurando la infraestructura urbana ambiental y ecológica con la estructura urbana existente. Con ello se busca incluir los valores tangibles e intangibles del patrimonio local en el desarrollo urbano al conectar barrios y tramas discontinuas de los cerros en Valparaíso, enlazando redes sociales preexistentes, potenciando nuevos intercambios económicos, etc., por medio de nuevos lugares con accesibilidad, incorporar equipamientos y servicios urbanos, los cuales aseguran su cuidado a través de su apropiación en la estructura social asociada en sus deslindes.

\section{Metodología, observación arquitectónica y territorial}

Se trata de una investigación orientada al diseño, donde el proyecto es la instancia de constatación de la hipótesis. Este estudio se desarrolla en el contexto académico de un Taller de Proyecto Urbano en cuarto año de la carrera de Arquitectura, en el marco del Taller Integrado, asignatura de Diseño Arquitectónico que integra materias de proyecto, localización, territorio y paisaje cultural.

Se utiliza el método de la planificación ecológica, que analiza los sistemas biofísicos y socioculturales del lugar para definir las mejores áreas donde deben localizar los nuevos usos de suelo específicos. Se trata de una adaptación del modelo descriptivo biofísico (McHarg, 2000), que ve los componentes de la identidad natural y construida de la ciudad como un sistema de valores potenciales (valores ambientales, culturales y de desarrollo económico) y debilidades del territorio (riesgos y carencias entre otras) que ofrecen oportunidades para el uso humano.

Primero, se recoge la información a través de la observación arquitectónica, que incorpora formas de conocer el entorno a partir de la percepción sensorial, poética, estética y fenomenológica del lugar que se analiza, recogiendo la relación del habitante con su espacio/lugar, tal como dice Norberg-Schulz "la arquitectura debe respetar el lugar, integrar con ella, escuchar, es decir, su genius loci. Esta es una expresión típica romana conectado a todo lo que el lugar es y quiere ser" (Norberg-Schulz, 1979). Esta observación arquitectónica se acompaña con la conversación con los habitantes, lo que permite tener mejor comprensión de la cultura local. Así, los PUE cuentan con antecedentes que permiten dar una respuesta multiescalar a las intervenciones.

Este estudio se traduce en croquis con observaciones y mapas de distribución espacial de la información (valores). Además, es necesario conocer las tensiones, recorridos, redes y ritmos propios de la ciudad. Toda esta 
información se lleva a planos temáticos, que permiten comprender las dinámicas, los valores y características que dan identidad a este sistema urbano.

Una vez comprendido el desarrollo urbano territorial de Valparaíso (visión sistémica), las características internas y externas del sistema actual (análisis FODA), es posible formular las estrategias de acción para la visión de futuro de la ciudad, definiendo la localización e identidad de los PUE del Plan General de ordenamiento territorial. Como parte del proceso de diagnóstico urbano crítico se elaboran diagramas de síntesis, los que son fundamento de la estrategia de ordenamiento territorial.

Este método, que permite orientar el desarrollo de la ciudad poniendo en valor el paisaje cultural, es el desarrollado en el Taller de Arquitectura de la Universidad de Valparaíso. Este se compromete con el desarrollo de principios relacionados con el sistema de valores (tangible e intangible), los que deberán incluirse al momento del emplazamiento de los PUE y en sus criterios de diseño, de manera tal que aseguren los recursos de la ciudad. Para efectos del estudio y de poder hacer una evaluación más precisa del objetivo/resultado de diseño esperado/logrado de cada PUE desarrollado, se distinguen tres líneas de acción sobre los valores tangibles e intangibles, esto es, criterios: urbanos/culturales, ambientales/naturales y paisajísticos/territoriales.

\begin{tabular}{|c|c|}
\hline Urbanos/culturales & $\begin{array}{l}\text { Criterios de diseño orientados a la organización } \\
\text { social, política y económica y al desarrollo de la } \\
\text { equidad social, permiten dar acceso a los } \\
\text { servicios (infraestructura, } \\
\text { equipamientos y servicios) y apoyo al desarrollo } \\
\text { económico a través de maximizar el uso de los } \\
\text { recursos locales (sociales y productivos). }\end{array}$ \\
\hline Ambientales/naturales & $\begin{array}{l}\text { Criterios de diseño orientados a la preservación } \\
\text { de los fenómenos naturales en la ciudad, } \\
\text { minimización de situaciones riesgo para las } \\
\text { personas, y potenciando el desarrollo de una } \\
\text { ciudad-natural e identidad territorial. }\end{array}$ \\
\hline Paisajísticos/territoriales & $\begin{array}{l}\text { Criterios de diseño orientados a cuidar el paisaje } \\
\text { natural al interior de la ciudad, participando de } \\
\text { los fenómenos naturales como fuentes de } \\
\text { recursos (energía y salud), poniendo en valor el } \\
\text { ecosistema del territorio, reconociendo al ser } \\
\text { humano como parte de este, así como dar valor } \\
\text { a la construcción de su paisaje cultural, } \\
\text { generando mayor arraigo e identidad territorial. }\end{array}$ \\
\hline
\end{tabular}


Tabla 1

Síntesis de criterios de diseño según lineamientos urbanos, ambientales y paisajísticos

\begin{tabular}{|c|c|c|c|}
\hline $\begin{array}{c}\text { Líneas de } \\
\text { acción }\end{array}$ & Objetivos & Valores tangibles & Valores intangibles \\
\hline Urbanos & 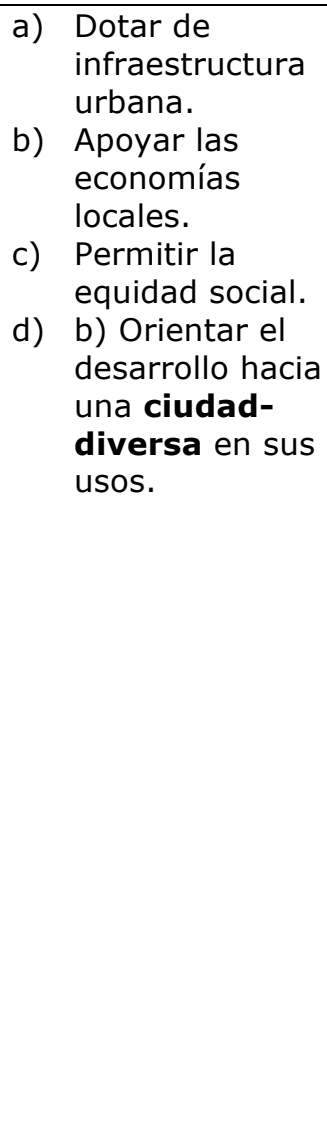 & 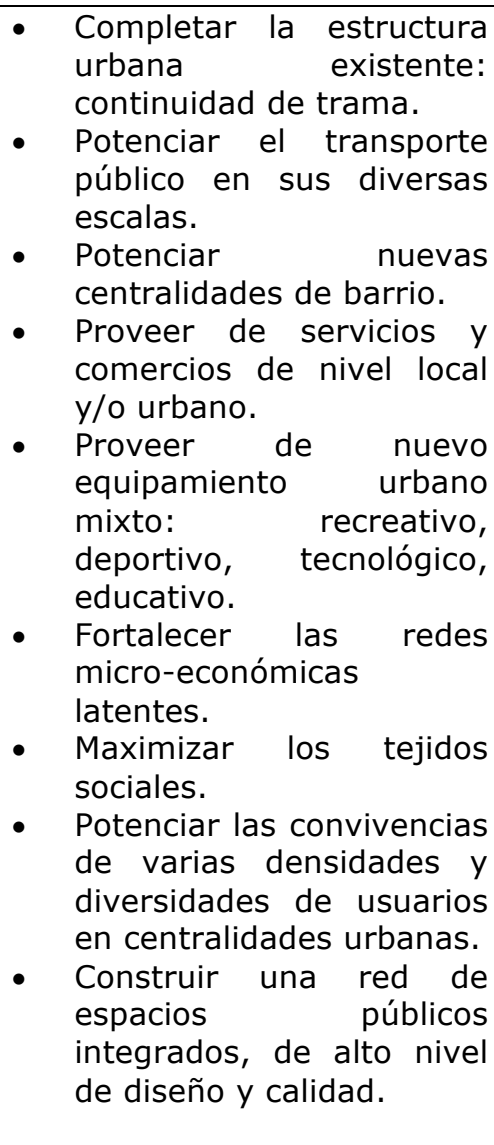 & 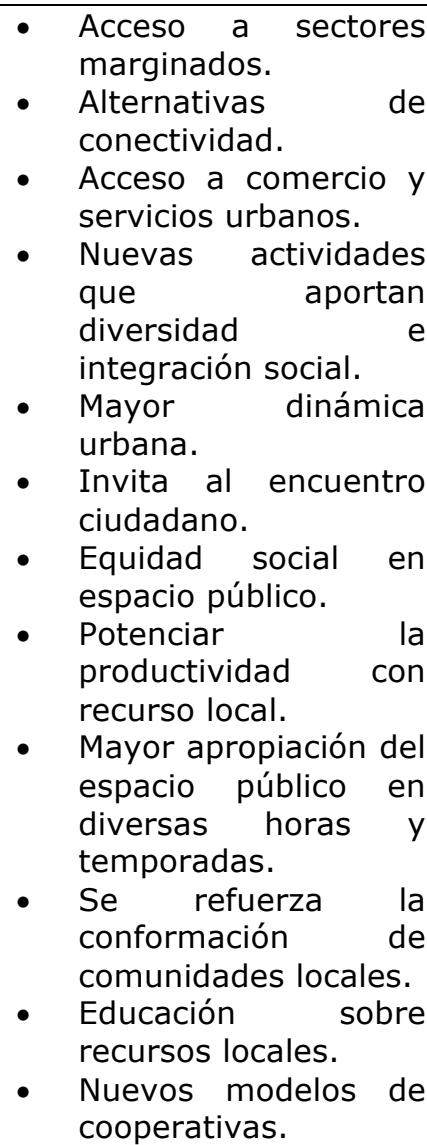 \\
\hline Ambientales & 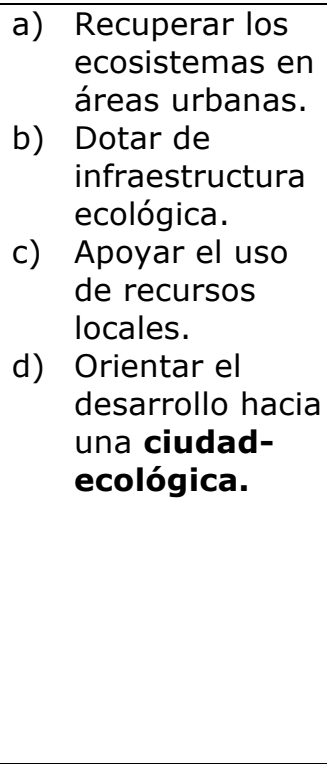 & 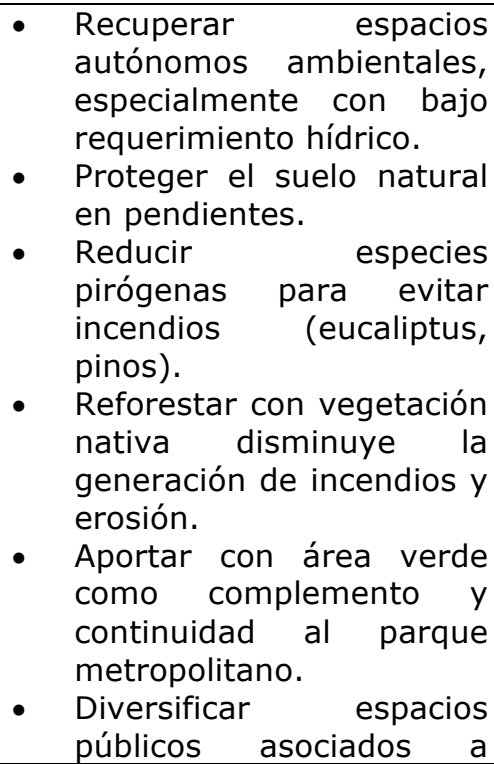 & 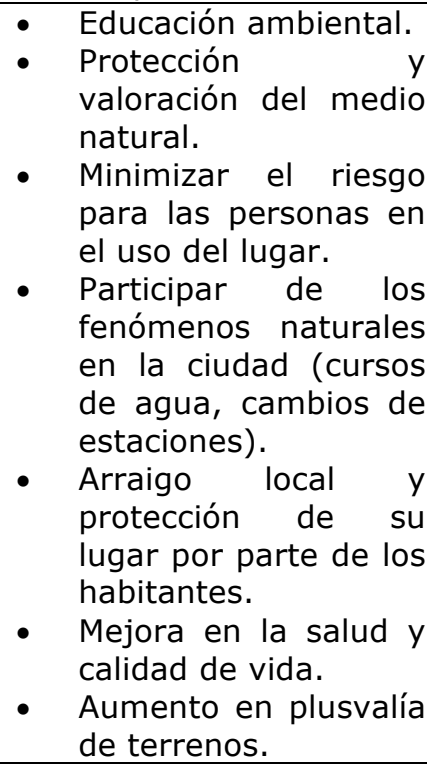 \\
\hline
\end{tabular}




\begin{tabular}{|c|c|c|c|c|}
\hline & & & $\begin{array}{l}\text { nuevos programas } \\
\text { ambientales. } \\
\text { Incluir infraestructura que } \\
\text { integre el ciclo del agua y } \\
\text { la gestión hidrológica. de } \\
\text { - Recuperación de de } \\
\text { biodiversidad a través de } \\
\text { la flora y fauna nativas. } \\
\text { Incluir construcción y } \\
\text { arquitectura sustentable: } \\
\text { - diseño biofílico. } \\
\text { - uso de materiales } \\
\text { con criterios de } \\
\text { sustentabilidad. } \\
\text { - reducir el consumo } \\
\text { energético. }\end{array}$ & 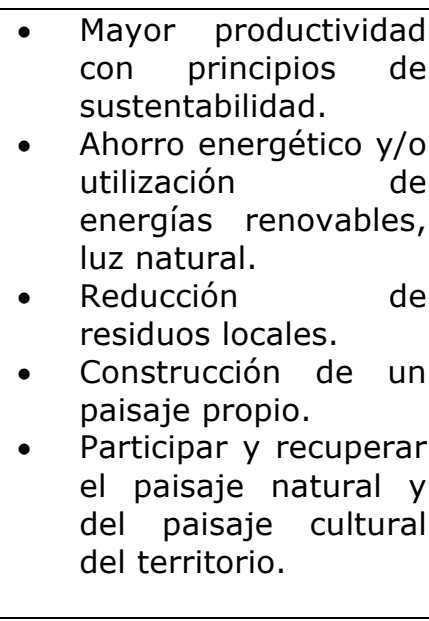 \\
\hline Paisajísticos & & $\begin{array}{l}\text { Poner en valor } \\
\text { el paisaje } \\
\text { natural/cultural } \\
\text { Potenciar la } \\
\text { identidad } \\
\text { territorial. } \\
\text { Orientar el } \\
\text { desarrollo hacia } \\
\text { una ciudad- } \\
\text { territorial. }\end{array}$ & $\begin{array}{l}\text { - Localizar los espacios } \\
\text { públicos en directa } \\
\text { relación con su territorio } \\
\text { (vistas, morfología). } \\
\text { - Configurar el perfil } \\
\text { urbano con elementos } \\
\text { naturales y construidos. } \\
\text { - Adecuar el diseño de las } \\
\text { obras a las condiciones } \\
\text { del lugar (genius loci). } \\
\text { - Recuperación de la flora y } \\
\text { fauna, de la biodiversidad } \\
\text { del paisaje propio de } \\
\text { quebradas y sus } \\
\text { microclimas. vas las } \\
\text { Poner en valor las } \\
\text { diversas unidades de } \\
\text { paisaje del territorio. } \\
\text { (Nogué y Sala, 2006). }\end{array}$ & 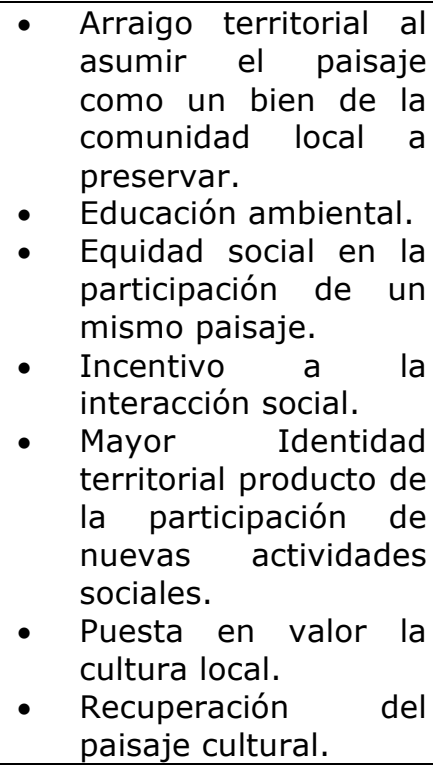 \\
\hline
\end{tabular}

Fuente: Elaboración propia.

\section{Una propuesta multiescalar para valparaíso}

"Valparaíso es un testimonio excepcional de la fase temprana de globalización, a fines del siglo XIX, cuando se convirtió en el puerto comercial líder de las rutas marítimas de la costa del Pacífico de Sudamérica" (Organización de las Naciones Unidas para la Educación, la Ciencia y la Cultura, Unesco, 2014).

Así se va configurando esta morfología que debe adaptarse a estas condiciones abruptas de su topografía, pero que a su vez significó la aparición de un paisaje y cultura local que hoy es de reconocimiento internacional. En Valparaíso, el paisaje cultural es su identidad territorial.

Se postula que, en el contexto actual de globalización y puesta en valor del medio natural en las ciudades, se ofrece una nueva oportunidad a Valparaíso, 
especialmente por encontrarse en un momento de crisis (incendios, terremotos, tsunamis). Por ello, se propone pensar la revitalización de la ciudad desde la recuperación de sus valores tangibles e intangibles.

El trabajo considera tres etapas para su desarrollo.

Etapa 1: Visión de desarrollo futuro para Valparaíso. Luego del estudio urbano crítico y multiescalar del territorio, se acuerda la visión del desarrollo futuro para Valparaíso. Esta visión de desarrollo se fundamenta en potenciar las oportunidades que ofrece la Región como hotspot ecológico de la biósfera, como red de puertos en el corredor bioceánico y como red turística cultural de la macro zona central del Chile. De este modo, se da continuidad al corredor ecológico regional a través de las principales quebradas en Valparaíso, buscando revertir la condición de riesgo ambiental de estos cauces naturales, actualmente convertidos en vertederos informales y espacios para ocupación ilegal de terrenos o tomas.

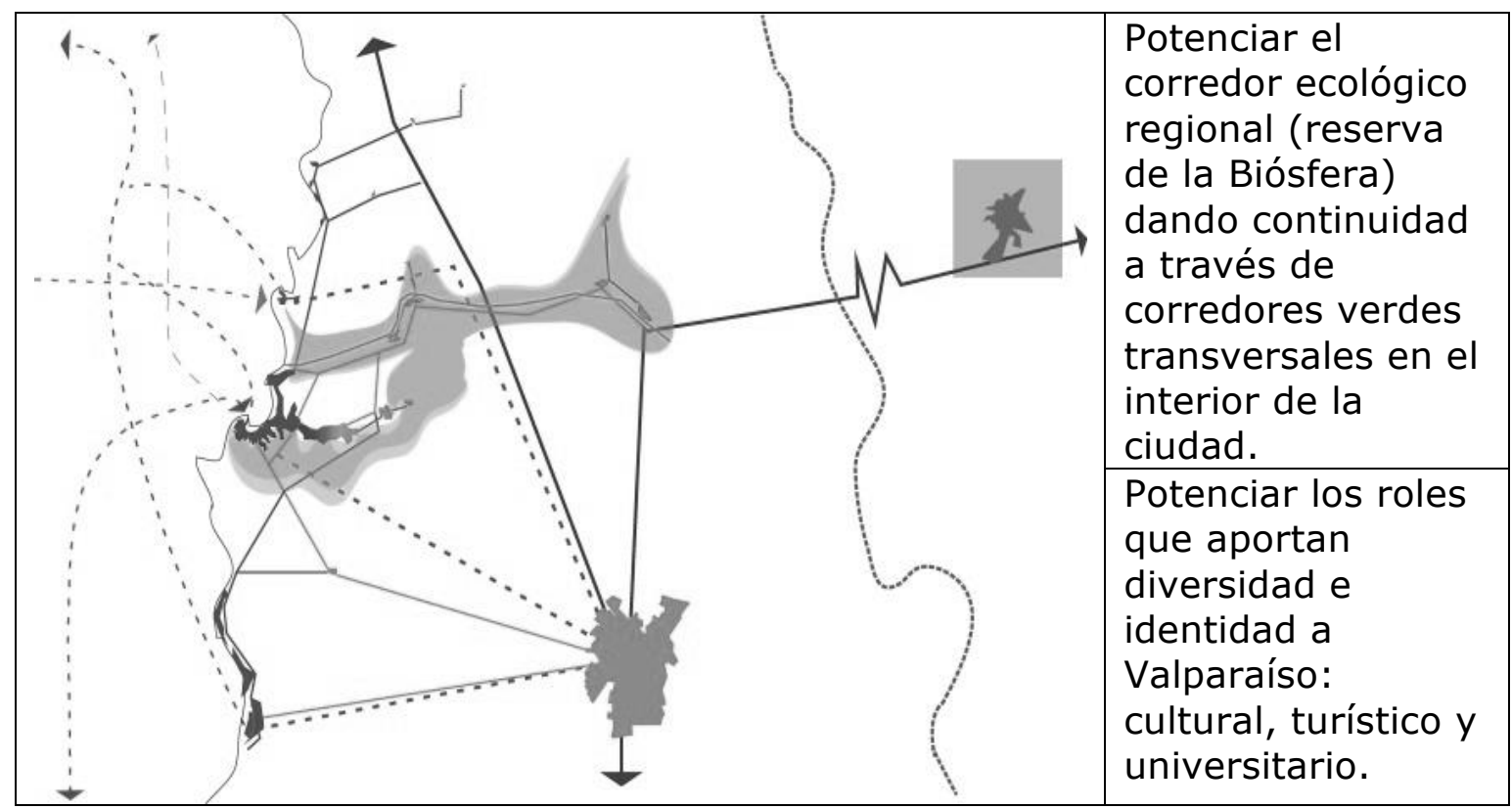

Figura 2. Visión de desarrollo futuro para Valparaíso / Escala regional. Fuente: Paola Leiva. Elaboración del Taller Integrado ARQU TIT 31/ Escuela de Arquitectura/ Universidad de Valparaíso/ 2014. 
Tabla 2

Propuesta de roles de la visión de desarrollo/Escala comunal

\begin{tabular}{|c|c|c|c|}
\hline \multirow[b]{2}{*}{$\begin{array}{l}\text { Corredor ecológico } \\
\text { Reserva de la Biosfera; } \\
\text { Parque Laguna verde; } \\
\text { Quebradas comunales. }\end{array}$} & Corredor turístico & \multicolumn{2}{|c|}{ Corredor comercial } \\
\hline & $\begin{array}{l}\text { Red de atributos } \\
\text { regionales; } \\
\text { red de espacios públicos. }\end{array}$ & \multicolumn{2}{|c|}{$\begin{array}{l}\text { Red intercambio bio- } \\
\text { oceánico; macro zona } \\
\text { central red de puertos de } \\
\text { región. }\end{array}$} \\
\hline $\begin{array}{c}\text { Sustentabilidad } \\
\text { ambiental }\end{array}$ & Sustentabilid & \multicolumn{2}{|c|}{$\begin{array}{l}\text { Sustentabilidad } \\
\text { económica }\end{array}$} \\
\hline 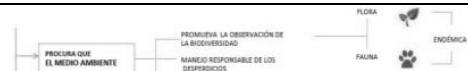 & Aftr ar & Vsion Ambto economico & $\begin{array}{l}\text { Benefricis economicos } \\
\text { de ecociudad }\end{array}$ \\
\hline 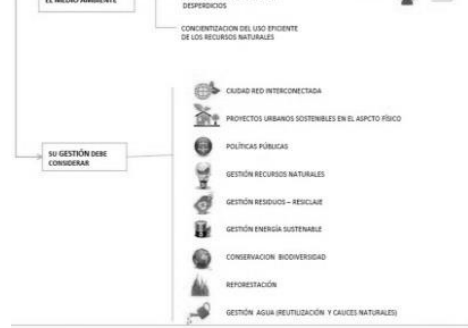 & 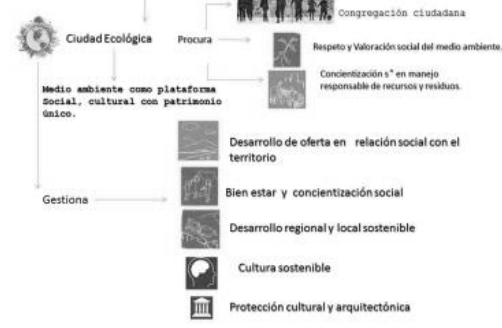 & 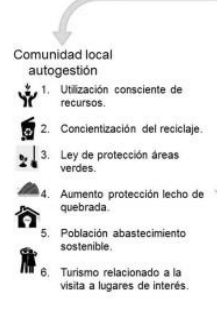 & 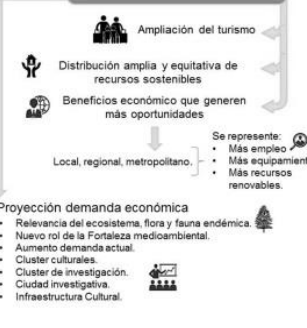 \\
\hline
\end{tabular}

Fuente: Elaboración del Taller Integrado ARQU TIT 31/ Escuela de Arquitectura/ Universidad de Valparaíso/2014.

\section{Contrastación de hipótesis}

- Las quebradas en Valparaíso se reconocen como parte de un sistema urbano complejo mayor, que se caracteriza por sus diversos roles.

- Las quebradas se plantean como parte de un sistema conectado a la escala regional (visión multiescalar).

Etapa 2: Plan General, Estrategia de Ordenamiento Territorial para Valparaíso. Se propone una nueva estructura ecológica urbana territorial a través de corredores verdes, configurada por nuevas infraestructuras de servicio, que completan el sistema de redes de conectividad, favorecen el desarrollo de múltiples y variadas centralidades sobre la base de los elementos de la estructura urbana existente. Con ello se busca poner en valor los ejes transversales como un nuevo sistema de espacios públicos interconectados. 


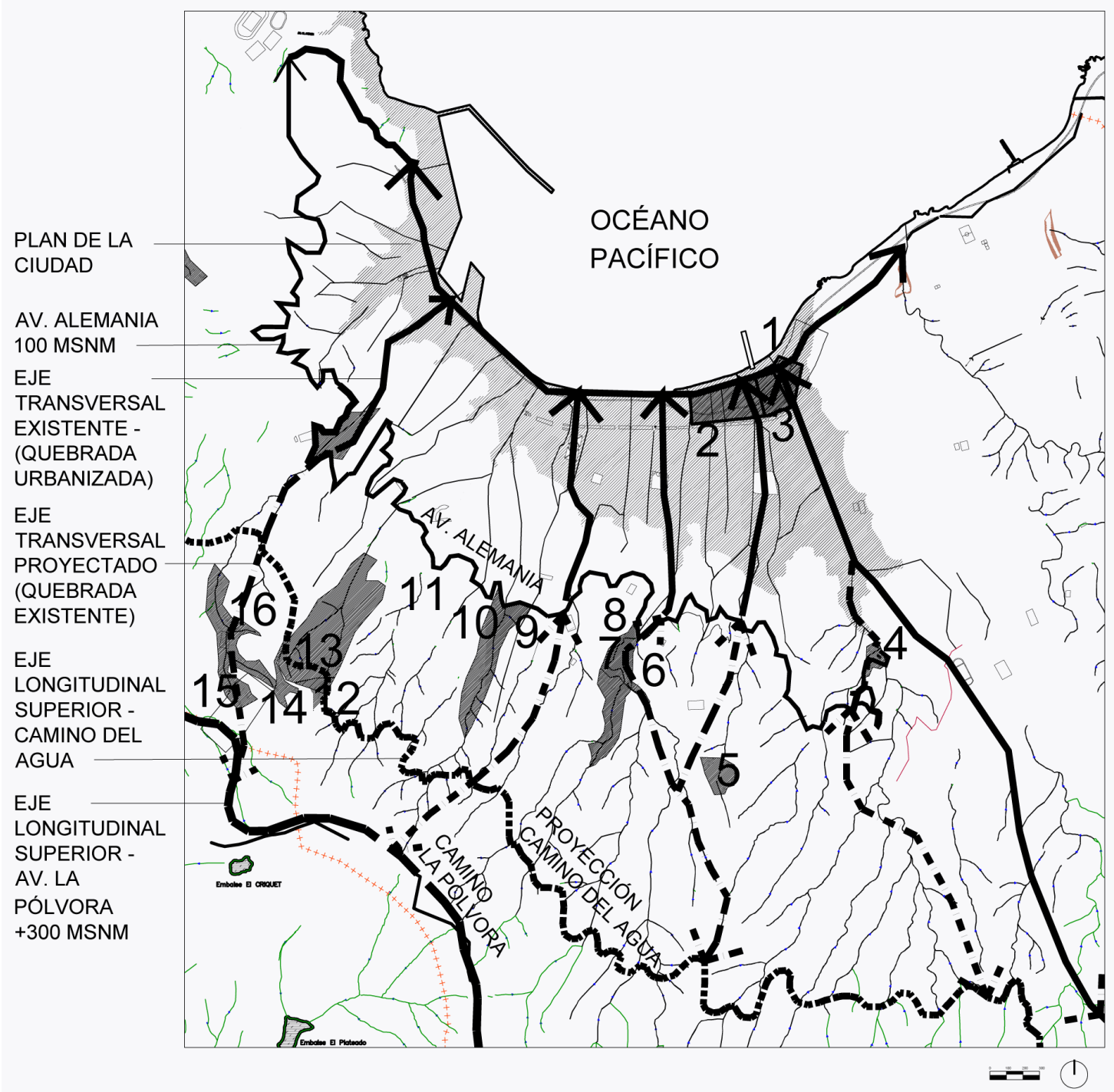

Figura 3. Localización de Proyectos Urbanos en Estrategia de Ordenamiento Territorial.

Fuente: Elaboración propia en base a desarrollo del Taller Integrado ARQU TIT 31/ Escuela de Arquitectura/ Universidad de Valparaíso/2014.

La ubicación de los PUE se asocia con los nuevos ejes longitudinales (Camino Cintura y Camino del Agua) y las quebradas, configurando los corredores verdes. 
Tabla 3

Listado de Proyectos Urbanos Estratégicos del Plan General de Ordenamiento Territorial/ Escala comunal

\begin{tabular}{|c|l|l|}
\hline No & \multicolumn{1}{|c|}{ Proyecto Urbano Estratégico } & \multicolumn{1}{c|}{ Estudiante } \\
\hline 1 & Parque del agua en borde costero & Lyubitza Albanecich \\
\hline 2 & Parque intermodal de Borde & Sebastián Segura \\
\hline 3 & Plaza Mirador Plan/Cerro & Rocío Pedreros \\
\hline 4 & Centro universitario patrimonial & Ronny Cataldo \\
\hline 5 & Centro de barrio & Marcelo Santibáñez \\
\hline 6 & Estación de bomberos y control ambiental & Jorge Cárdenas \\
\hline 7 & Parque del agua en quebrada & Rita Grandón \\
\hline 8 & Parque de la salud & Madelyn Aguilera \\
\hline 9 & Reocupación de quebrada & Karina Toro \\
\hline 10 & Parque urbano cultural & Paola Leiva \\
\hline 11 & Centro cultural turístico & Paula Vilches \\
\hline 12 & Centro de apoyo a la infancia & Angélica Olivares \\
\hline 13 & Parque interactivo del ecosistema & Adolfo Guzmán \\
\hline 14 & Centro cultural educativo & Ignacio Barrera \\
\hline 15 & Centro educativo de borde parque & Marcelo Vargas \\
\hline 16 & Parque educativo & Soledad Vidal \\
\hline 17 & Parque centro exploración flora nativa & Daniela Muñoz \\
\hline
\end{tabular}

Fuente: Elaboración del Taller Integrado ARQU TIT 31/ Escuela de Arquitectura/ Universidad de Valparaíso/2014.

\section{Contrastación de hipótesis}

- La generación de nuevas vías necesarias para dar continuidad a la trama, así como potenciar y dar cabida en el diseño urbano al sistemas de transporte colectivo (teleférico, nuevos recorridos de buses, circuitos peatonales y ciclo- vías) logra completar la trama urbana existente y se generan nuevas y variadas opciones de accesibilidad a estos sectores, actualmente marginados de los servicios urbanos. Se ofrecen así nuevas oportunidades de desarrollo sustentable.

- Las quebradas se plantean ahora como piezas urbanas integradas al sistema general de ciudad, como parte de un sistema conectado, de escala local (visión multiescalar).

- Todos los PUE que se emplazan en las quebradas responden en mayor o menor medida a los criterios de diseño detallados en Tabla 1, sobre la base de puesta en valor de los elementos que configuran el paisaje cultural en Valparaíso. 
Etapa 3: Proyectos Urbanos Estratégicos. Se presentan diversos Proyectos Urbanos Sustentables asociados a comunidades locales y a localizaciones de impacto urbano. Los casos son los siguientes:

\begin{tabular}{|c|c|}
\hline $\begin{array}{c}\text { Propuesta de centros de } \\
\text { educación ambiental } \\
\text { (Adolfo Guzmán, } \\
\text { proyecto } 13 \text { en plano } \\
\text { estrategia de } \\
\text { ordenamiento territorial) }\end{array}$ & $\begin{array}{l}\text { Parque interactivo del ecosistema, ubicado en el } \\
\text { cruce del Camino La Pólvora con el barrio } \\
\text { Montedónico, en parte alta de Playa Ancha, } \\
\text { concebido para la difusión de flora nativa de la } \\
\text { zona central, tanto a las comunidades locales } \\
\text { como de la macrociudad, a través de una } \\
\text { diversidad de talleres y actividades de desarrollo } \\
\text { científico. }\end{array}$ \\
\hline
\end{tabular}

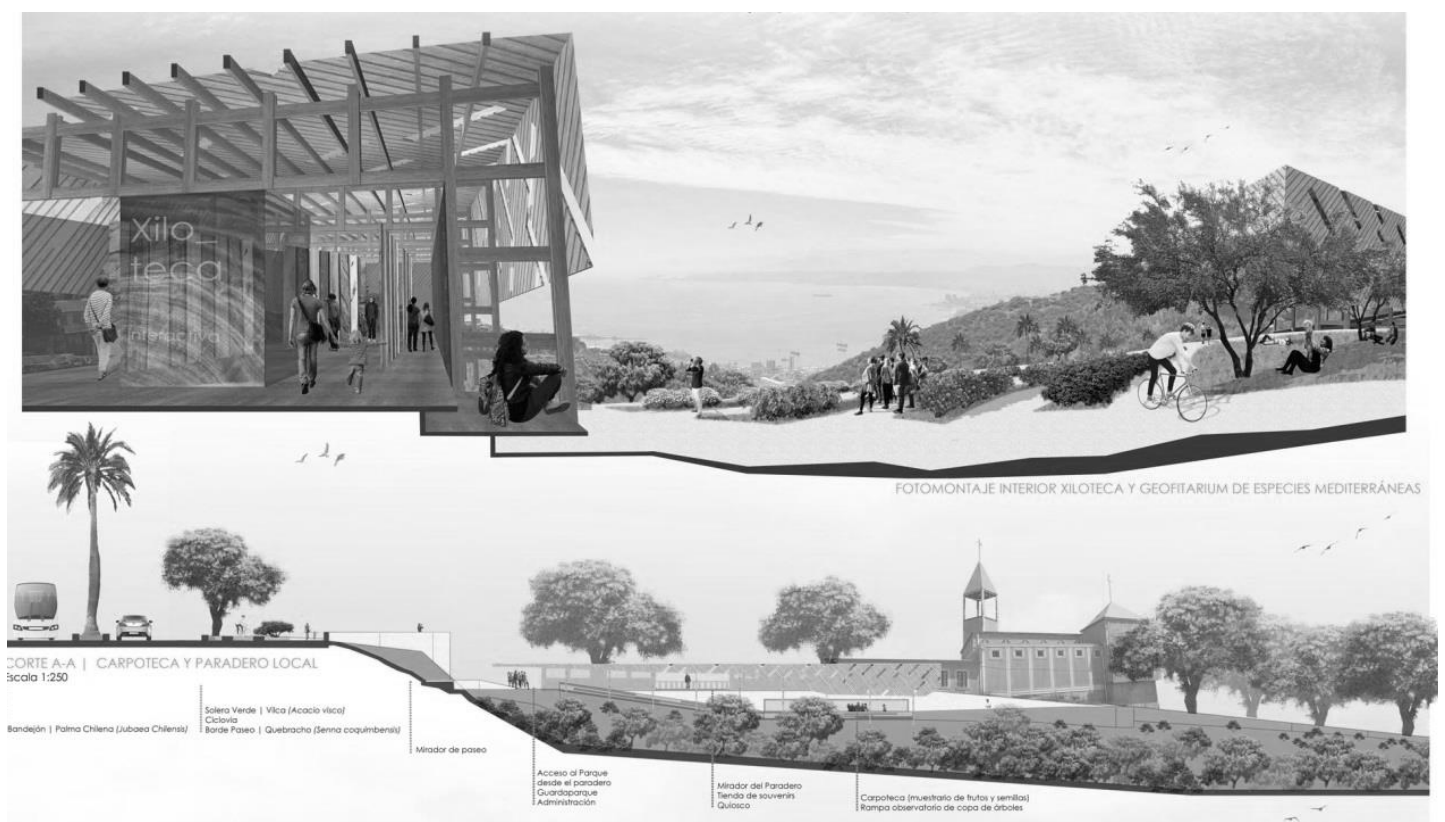

Figura 4. Parque interactivo del ecosistema.

Fuente: Adolfo Guzmán. Elaboración de proyecto en Taller Integrado ARQU TIT 31/ Escuela de Arquitectura/ Universidad de Valparaíso/ 2014.

\section{Contrastación de hipótesis}

- Completa la estructura urbana existente de la ciudad, relacionando áreas inaccesibles de la trama superior del cerro con la estructura intermedia, Av. Alemania (valor tangible), dando acceso a grupos sociales vulnerables (valor intangible).

- Potencia nueva centralidad de barrio (valor tangible) aportando a la educación ambiental y responsabilidad social, como a la generación de actividades de microeconomía local, incorporando la participación de los habitantes del sector (patrimonio intangible). 
- Incorpora nuevos espacios de uso público y recupera el paisaje original de la quebrada con el uso de flora nativa y protección de las pendientes, lo cual disminuye la generación de incendios (valor tangible). De esta manera se aporta a la identidad territorial y recuperación del paisaje cultural (valor intangible).

\section{Estación de bomberos y control ambiental (Jorge Cárdenas, proyecto 6 en plano estrategia de ordenamiento territorial)}

Estación de bomberos y control ambiental,
ubicado en el cruce de Avenida Alemania y las
cercanías de la continuación de Av. Francia.
Centro de respuesta a los incendios en parque
de acceso público con área de ejercitación
para bomberos de la comuna y centro
educativo del medio ambiente natural.

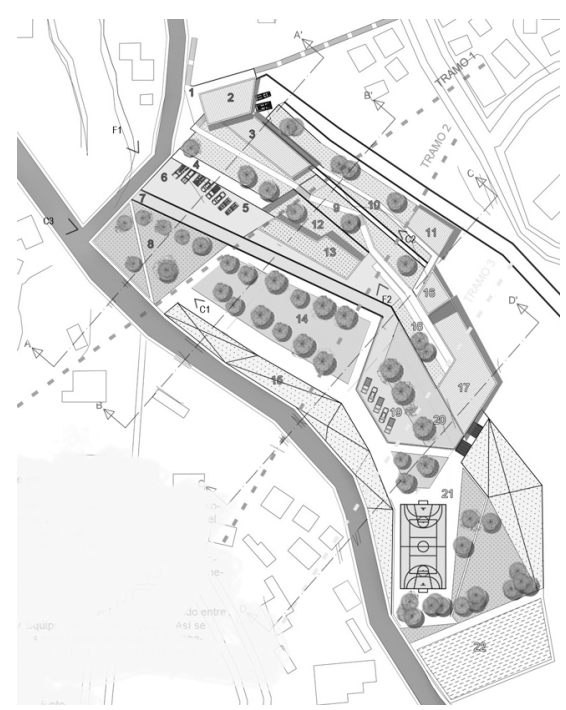

Figura 5. Estación de bomberos y control ambiental.

Fuente: Elaboración de proyecto en Taller Integrado ARQU TIT 31/ Escuela de Arquitectura/ Universidad de Valparaíso/ 2014

\section{Contrastación de hipótesis}

- Completa la estructura urbana existente de la ciudad a través de la conexión peatonal entre Av. Alemania y el sector superior (valor tangible). Mejora la accesibilidad a sectores marginados de la trama urbana. Aporta diversidad social e integración entre los habitantes (valor intangible) a través de las nuevas actividades

- Creación de un espacio público de sensibilización y cuidado del medio ambiente relacionado con el tema de incendios (valores intangibles), incluyendo manejo de la vegetación en sus pendientes cercanas (valor tangible). Protección del suelo para evitar erosión a través del manejo de taludes, uso de vegetación, agua y humedad ambiental. 
- La forma del proyecto se adapta a la pendiente y descuelga sus actividades siguiendo la topografía natural del terreno, a modo de la ocupación de estos terrenos en cerro (valor tangible). Así se pone en valor el paisaje local (valores intangibles).

\begin{tabular}{|c|c|}
\hline $\begin{array}{l}\text { Parque intermodal de } \\
\text { borde (Sebastián Segura, } \\
\text { proyecto } 2 \text { en plano } \\
\text { estrategia de } \\
\text { ordenamiento territorial) }\end{array}$ & $\begin{array}{l}\text { Parque intermodal de borde, ubicado en el } \\
\text { encuentro del Borde Costero, Avenida Argentina } \\
\text { y Avenida Francia, viene a configurar el frente } \\
\text { marítimo de la ciudad el nuevo espacio público } \\
\text { de borde mar, que a su vez es el nodo } \\
\text { intermodal que conecta la ciudad de Valparaíso } \\
\text { con las ciudades cercanas. Integra la estación } \\
\text { de tren, metro, trolebús, paradas de bus y } \\
\text { trasatlántico, un centro comercial, actividades } \\
\text { culturales y espacios de esparcimiento } \\
\text { asociadas a plazas y deportes acuáticos, } \\
\text { integrando en el proyecto la estructura de la } \\
\text { Bodega Simón Bolívar, edificio patrimonial } \\
\text { existente. }\end{array}$ \\
\hline
\end{tabular}




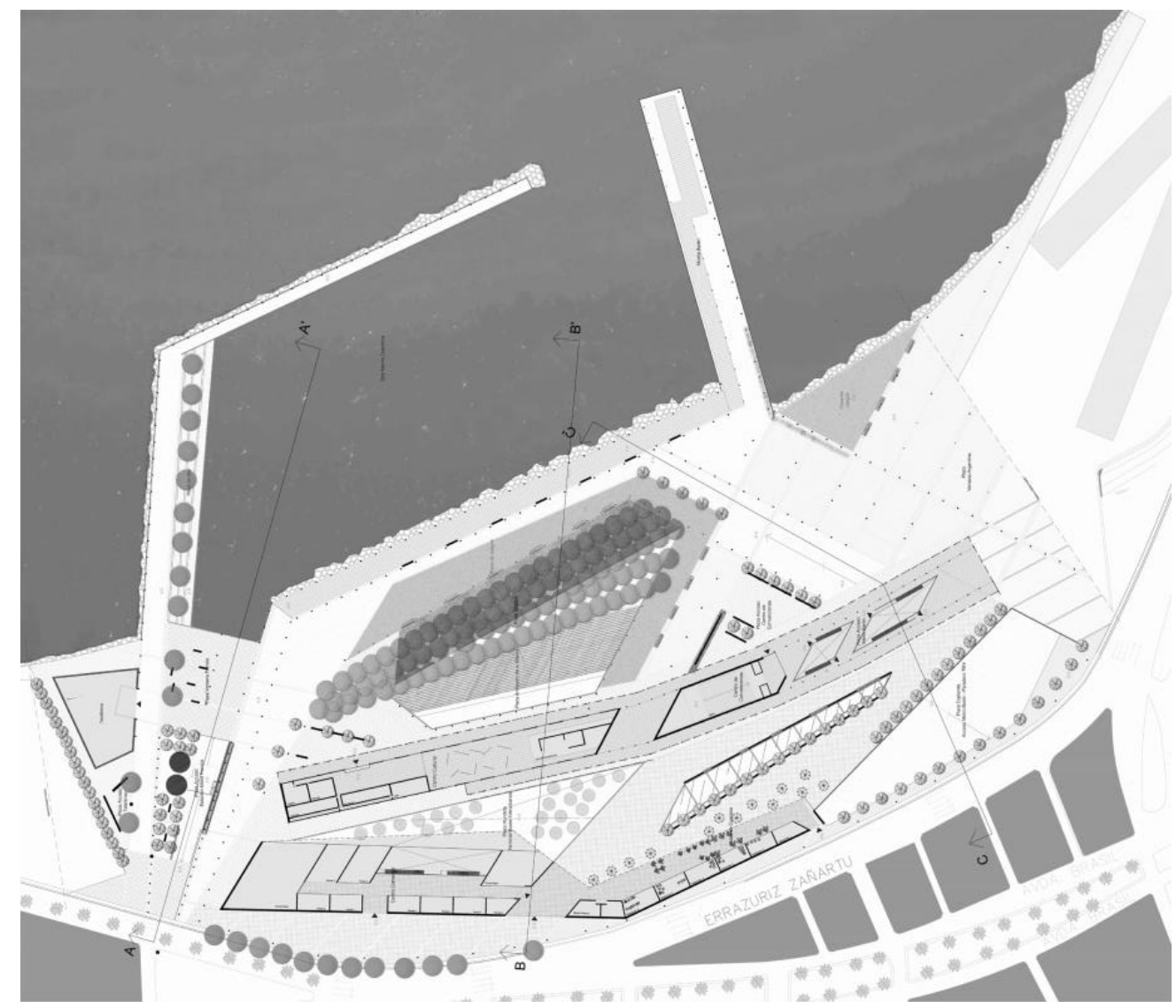

Figura 6. Parque intermodal de borde.

Fuente: Sebastián Segura. Elaboración de proyecto en Taller Integrado ARQU TIT 31/ Escuela de Arquitectura/ Universidad de Valparaíso/ 2014.

\section{Contrastación de hipótesis}

- Genera un nuevo frente marítimo para la ciudad y un remate en la llegada al mar de Av. Argentina, a través del diseño de edificios y espacio público que soportan la estación intermodal de trenes, buses y troles (valor tangible), generando un soporte de acceso a toda la comunidad de la ciudad, la región y visitantes internacionales (valor intangible).

- Potencia la centralidad del lugar, integrando múltiples programas asociados al borde mar, comercio y transporte (valor tangible), aporta a las dinámicas urbanas (valor intangible).

- Se plantea un diseño que incorpora el borde costero para el uso universal a través de amplios espacios públicos, incorporando actividades náuticas para todos sus visitantes (valor tangible). Se aporta a la identidad territorial y recuperación del paisaje cultural (valor intangible). 
Parque urbano cultural (Paola Leiva, proyecto 10 en plano estrategia de ordenamiento territorial)

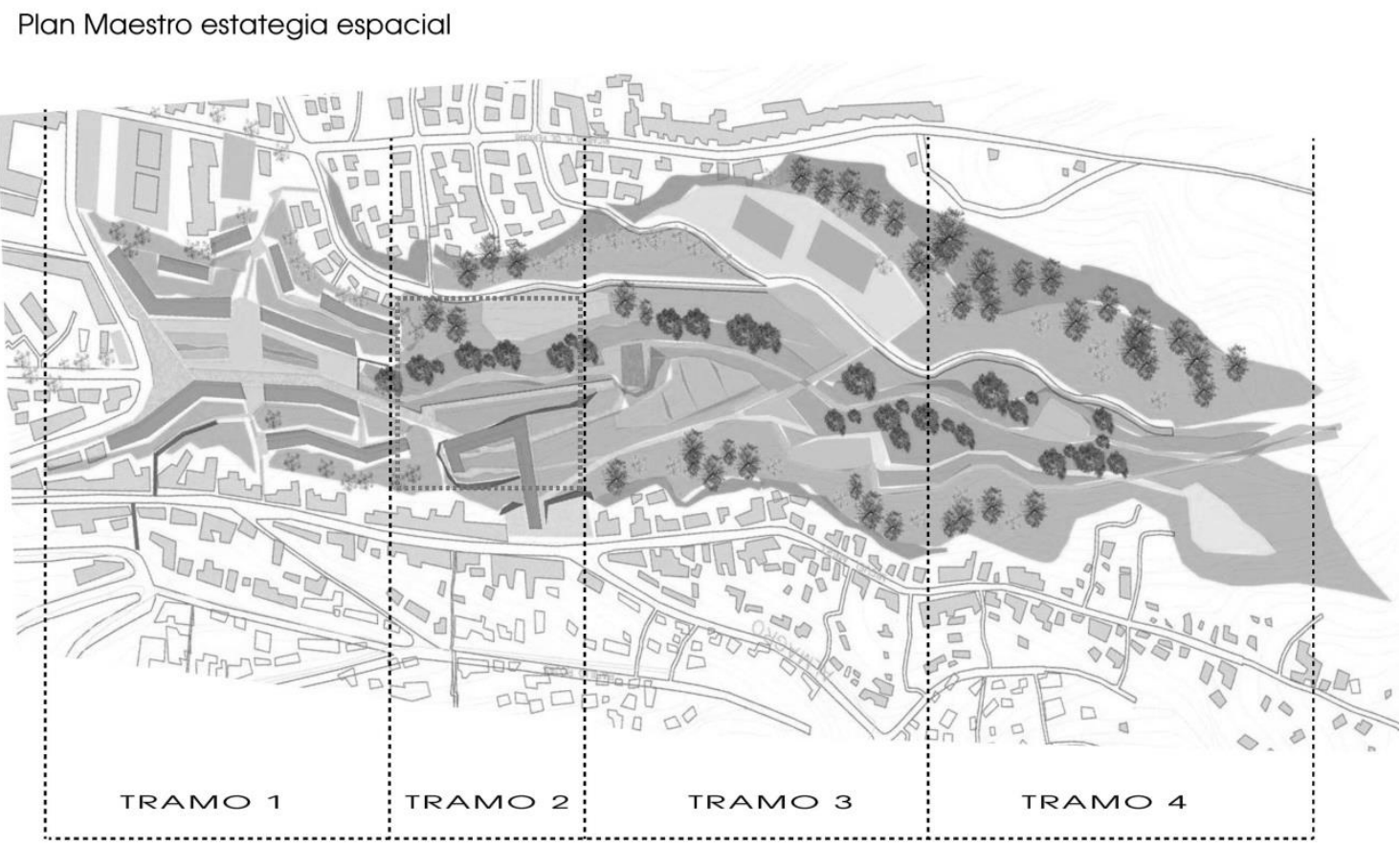

Figura 7. Parque urbano cultural.

Fuente: Paola Leiva. Elaboración de proyecto en Taller Integrado ARQU TIT 31/ Escuela de Arquitectura/ Universidad de Valparaíso/ 2014.

\section{Contrastación de hipótesis}

- El parque incluye vías que lo atraviesan, completa la estructura urbana existente de la ciudad, donde los principales aportes son la conformación de un centro de vivienda (densificando el sector) y comercio (entra servicios y equipamiento urbano) entre Av. Alemania y la Quebrada. El espacio público recoge el agua y conecta a un circuito cultural (valor tangible). La integración social y la generación de actividades de microeconomía local con el desarrollo de huertos urbanos son efectos de la nueva propuesta local (valor intangible).

- Manejo del agua a lo largo de la quebrada, cualificando cuatro tramos ambientales con programas diferenciados: el primero, de retención de agua asociado al espacio público comercial y viviendas, integrado a Av. Argentina. El segundo es donde el sonido del agua aísla al lector del centro cultural y biblioteca. Los dos tramos superiores de desarrollo natural del parque se deja correr agua entre la vegetación, a través del manejo de taludes, previo a la contención del agua en estanque superior (valores tangibles). Esto significa la recuperación de la quebrada así como una 
solución ambiental, lo que se traduce en una mejora de la habitabilidad de los espacios públicos y verdes que actualmente son los lugares perdidos de la ciudad (valor intangible).

- Entrega espacios públicos verdes para la comunidad local como para toda la ciudad (valor tangible), lo que tiene como objetivo ofrecer una mejor calidad de vida a los habitantes, de lugares de encuentro como de relación con naturaleza, integra el medio natural al construido (valor intangible).

\section{Centro cultural educativo (Ignacio Barrera, proyecto 14 en plano estrategia de ordenamiento territorial)}

Ubicado en el cruce del Camino de la Pólvora con el barrio Montedónico, en la parte alta de Playa Ancha. Acoge con un nuevo diseño un espacio público latente en el centro del barrio local, integrando un centro educativo y biblioteca para la comunidad local y la ciudad.

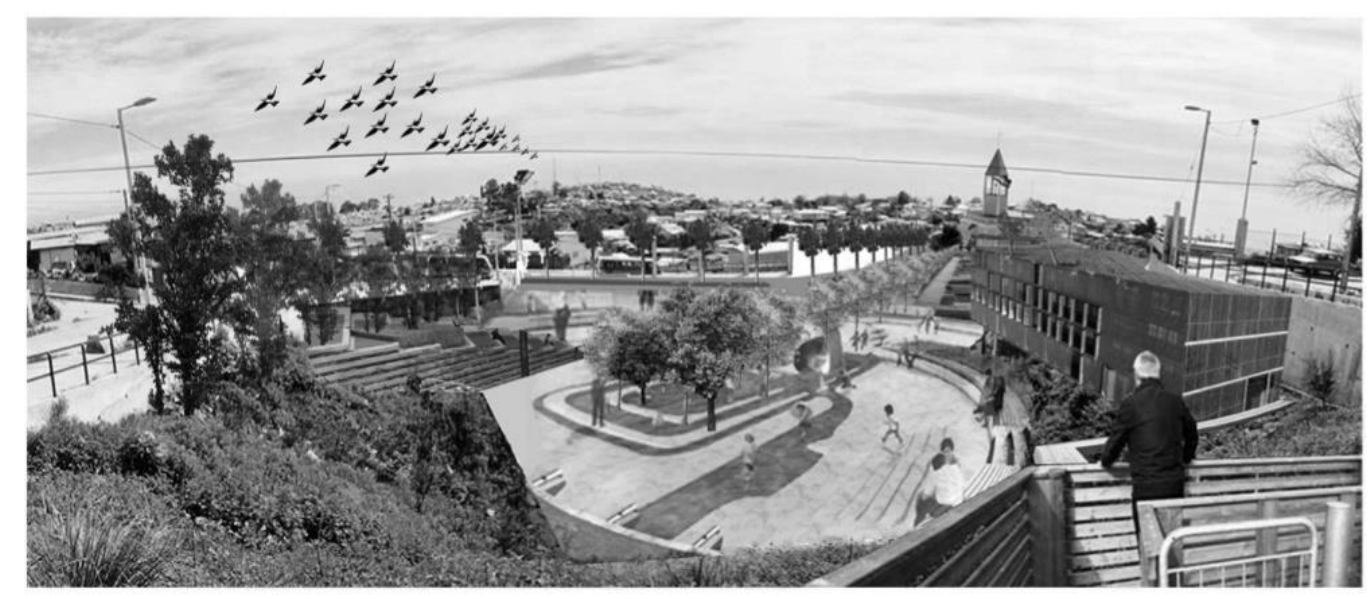

Figura 8. Centro cultural educativo.

Fuente: Ignacio Barrera. Elaboración de proyecto en Taller Integrado ARQU TIT 31/ Escuela de Arquitectura/ Universidad de Valparaíso/ 2014.

\section{Contrastación de hipótesis}

- Completa la estructura urbana existente en un sector actualmente de marginalidad, con espacios públicos diversos, equipamiento y servicios locales. Desarrollo del modelo de estructura barrial (valor tangible) donde el principal aporte es la integración social (valor intangible).

- El diseño incorpora nueva vialidad y vegetación asociada (valor intangible). Se ocupa de la difusión de educación ambiental y participación y responsabilidad de los habitantes (valor intangible). 


\section{Resultados}

Síntesis de los resultados de los PUE. Como resultados de la localización y diseño de los PUE en el sistema urbano Valparaíso, se puede concluir que, en general el aporte más relevante es que todos ellos contribuyen a mejorar la calidad de vida de los habitantes porteños. Esto es producto de contar con nuevos espacios públicos interrelacionados entre sí y con la trama urbana existente, lo que es muy importante para acoger y dar lugar al encuentro social.

Con la acción de un PUE y del conjunto de estos se impulsa la revitalización de estas áreas periféricas, se revierte la condición de abandono y deterioro, como también se busca alterar la obsolescencia ecológica funcional de los causes pluviales de las quebradas donde se emplazan, proponiendo en estos lugares subutilizados, nuevos sectores de centralidad urbana local. La localización de un nuevo servicio urbano como la elección del equipamiento urbano, son factores determinantes del arraigo e identidad territorial que cada sector adquiera, que invite a visitarlo y/o ser parte de esta nueva centralidad de Valparaíso. Así se ofrecen variadas opciones de encuentro social, de escala local, como urbana, incluso de escala regional, como es el caso del PUE en el sector costero del Muelle Barón.

Se integran, igualmente, áreas marginales a la ciudad, dando conectividad y accesibilidad al centro de la ciudad, relacionando las poblaciones existentes, conectando los fragmentos de trama y dando continuidad a la vialidad secundaria con las quebradas al integrarlas en la red urbana al mismo tiempo que protegen sus valores ambientales. Así se va configurando la nueva infraestructura urbana verde propuesta, que extiende los ejes transversales desde Avenida Alemania (eje longitudinal en los cerros a nivel de la cota 100) hasta la Avenida La Pólvora, vía de acceso superior de Valparaíso emplazada en nivel 300msnm.

Además, con estos PUE se revierte la condición de riesgo y fragilidad ambiental que presentan actualmente las quebradas, a través de incorporar el manejo del tipo de vegetación propia de estos ecosistemas y del borde superior de la ciudad, donde especies como el pino y el eucaliptus deberán ser minimizadas, de modo de evitar futuros incendios. Se rescatan las actuales áreas verdes y se da solución a los problemas urbanos de esta periferia superior a través de la inclusión de los valores que caracterizan a esta realidad social y territorial.

Evaluación de los valores de los PUE. En conjunto con esta síntesis de resultados de los PUE, se decide hacer una evaluación en los proyectos del estudio, a través de gráficos de valores tangibles e intangibles (urbanos, sociales, ambientales y paisajísticos) por proyectos PUE, que permiten visualizar el tipo y nivel de impacto que estos generarían en el área de intervención como en el entorno urbano, los que se aprecian a continuación: 


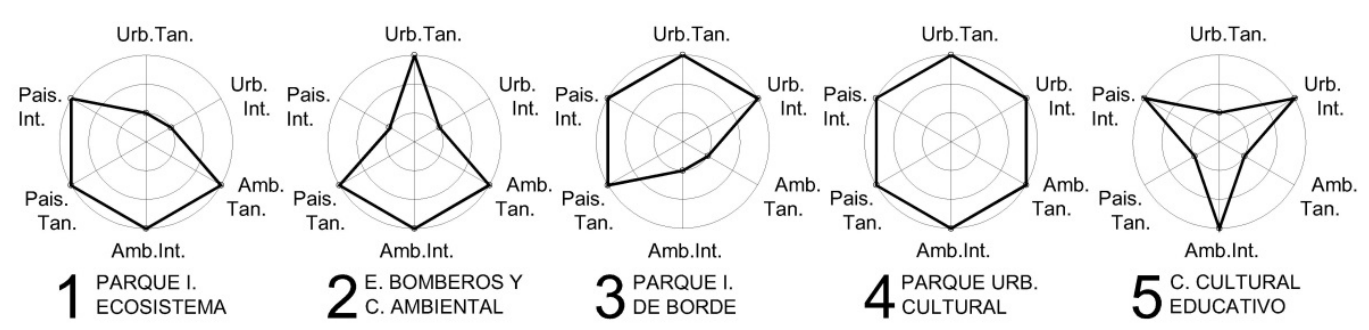

Figura 9. Comparación de los cinco proyectos descritos según sus valores urbano tangibles e intangibles, ambientales tangibles e intangibles y

Fuente: Elaboración propia.

paisajísticos tangibles e intangibles.

A través de los gráficos se aprecia que en general la evaluación del aporte o impacto (paisajístico, ambiental, social y urbano) que estos proyectos generan en la ciudad y sus habitantes es particular para cada proyecto, observándose que a grandes rasgos los proyectos tienden a inclinarse hacia algunos factores (sean estos valores tangibles o intangibles), como por ejemplo paisajístico y ambiental, urbano paisajístico y/o social.

Se puede concluir también que no existe un comportamiento homogéneo del impacto que genere una acción en el espacio urbano, ya sea en uno de los factores de diseño de proyecto por sobre otros, esto es propio de cada caso.

No existe relación directa entre tamaño y tipo de proyecto según sea su enfoque mayor (social, ambiental, urbano y paisajístico) en relación con el impacto que genere en los habitantes como en el espacio urbano, por ejemplo: el proyecto Parque intermodal de borde, emplazado en el frente mar no genera un impacto ambiental significativo, pero sí es un proyecto de alto impacto urbano paisajístico para los habitantes de Valparaíso, que luchan por recuperar el borde para la ciudad, lo que se traduce en un alto valor social (intangible). A diferencia del Centro cultural educativo, emplazado en el borde superior de Valparaíso, donde se aprecia que una menor acción directa, genera mayor impacto en todos los ámbitos, ambiental, social, urbano y paisajístico.

Pareciera ser que la localización del proyecto pasa a ser el factor más significativo en los impactos que genere, sean estos sociales, urbanos y/o ambientales.

\section{Conclusiones}

Primero, el nuevo rol del valor ambiental en la escala de la ciudad. Del trabajo desarrollado se observa que, en la medida que el factor principal en las estrategias de ordenación territorial sea el conjunto de valores ambientales, en 
diálogo con los valores urbanos y patrimoniales, se logrará tener una ciudad territorio o ciudad natural, donde la tendencia sería a la regeneración de los tejidos sociales y la recuperación de los ecosistemas.

La conformación morfológica de Valparaíso y el paisaje urbano, que refleja la historia que mantiene el territorio con sus habitantes, es actualmente la oportunidad para potenciar las quebradas como los espacios para la infraestructura ecológica (los ejes transversales verdes) para la ciudad.

Del mismo modo, la puesta en valor de las quebradas con su rol de ecosistema urbano y como unidades de paisaje en la ciudad permite dar una nueva accesibilidad a la parte superior de la ciudad e impulsa la apropiación del territorio a través de la localización de actividades diversas en lugares estratégicos, generando diversidad e integración social.

Podemos decir que, para entregar accesibilidad a los cerros y quebradas, la respuesta adecuada no es trazar una vialidad funcional conectora directa/lineal entre la parte baja urbana y la superior marginal. La nueva accesibilidad a través de las quebradas que se presenta en las propuestas permite diversas posibilidades de accesibilidad y configuración de una nueva, adaptada a la geografía del territorio, permitiendo mayor riqueza de relaciones sociales producto de generar variados modos de acceso (peatonal, vehicular y transporte público) y hacia diferentes lugares en las quebradas.

Segundo, los valores sociales como objetivos de diseño urbano. Como lineamientos del diseño urbano, se debiera definir en primera instancia los objetivos de bienestar social propios de las unidades locales preexistentes, reconocer sus valores, tangibles e intangibles, ya que estos orientarían las acciones concretas en el territorio. Por ejemplo, para lograr la integración de la ciudad, completando la trama inconexa de la ciudad en áreas marginales ( $y$ con ello mejorar la accesibilidad a servicios urbanos); se debiera incorporar las huellas de conectividad existentes como parte de la nueva trama urbana, de manera de no romper relaciones locales preexistentes y reforzar la convivencia histórica de las unidades vecinales existentes.

Reconociendo la necesidad de dar cabida al encuentro ciudadano a través de la construcción (diseño) de nuevos espacios públicos, es fundamental maximizar y magnificar las preexistencias de forma libre y poética según las vocaciones de los lugares en el territorio y su genius loci. De esta manera se está reforzando la identidad local, regenerando los tejidos sociales y recuperando los ecosistemas.

Parece pertinente rescatar los diversos modos de ocupación informal del espacio colectivo, su emplazamiento y usos informales de suelo que integran variados usos (deportivo + comercio + residencia + social + cultural), de manera de no romper las delicadas redes sociales $\mathrm{y} / \mathrm{o}$ productivas locales 
preexistentes (Varley, 2013). Al integrar estos variados usos de suelo en los PUE, se estarán entregando nuevas dinámicas urbanas, potenciando la convivencia de variadas densidades, en diversas horas y temporadas, y contribuyendo a la equidad social, así como a la formación de nuevos modelos de cooperativas a cargo de las nuevas actividades propuestas.

Tercero, la multiescalaridad de la apropiación del territorio. Aun cuando la multiescalaridad es parte esencial en los principios de diseño urbano pensar global y actuar local- se ha observado que, en la escala de ciudad, el factor principal lo determinan los valores ambientales, urbanos y patrimoniales, en la escala de barrio son los valores sociales, y en la escala de la habitabilidad lo determina la buena arquitectura. De este modo se integran la arquitectura con el urbanismo.

Por último, se puede concluir que, en la medida en que el PUE esté en directa relación - visual y/o perceptual- con la escala geográfica de la bahía de Valparaíso e incorpore las variables territoriales en su diseño, los habitantes que participen de esta nueva centralidad urbana local se reconocerán como parte de la ciudad, reforzando su identidad local, aun cuando se emplacen en los sectores más alejados (marginales) del centro histórico. 


\section{Referencias bibliográficas}

Amin, A. (2014). Lively infrastructure. Theory, Culture \& Society, 31(7-8), 137-161. https://doi.org/10.1177/0263276414548490

Ascensão, E. (2016). Interfaces of informality: When experts meet informal settlers. City, 20(4), https://doi.org/10.1080/13604813.2016.1193337

De La Maza, C. y Rodríguez, M. (2015). Sustentabiidad y biodiversidad urbana. Santiago: Ciencias Forestales y de la Conservación de la Naturaleza, Universidad de Chile.

Dovey, K. (2012). Informal urbanism and complex adaptive assemblage. International Development Planning Review, 34(4), 349-368. https://doi.org/10.3828/idpr.2012.23

Gauzin-Müller, D. (2002). Sustainable architecture and urbanism: Concepts, technologies, examples. Basel: Birkhäuser.

Fernández Güell, J. (1997). Planificación estratégica de ciudades. Barcelona: Editorial Gustavo Gilli, S.A.

Hidalgo, R., Santana, D., Alvarado, V., Arenas, F., Salazar, A., Valdebenito, C., y Álvarez, L. (Org.) (2016). En las costas del neoliberalismo. Santiago: Pontificia Universidad Católica de Chile, Instituto de Geografía y Pontificia Universidad Católica de Valparaíso, Instituto de Geografía.

Hough, M. (2004). Cities and natural process: A basis for sustainability. New York, Canada: Routledge.

Huchzermeyer, M. \& Misselwitz, P. (2016). Coproducing inclusive cities? Addressing knowledge gaps and conflicting rationalities between selfprovisioned housing and state-led housing programmes. Current Opinion in Environmental Sustainability, 20, 73-79. https://doi.org/10.1016/j.cosust.2016.07.003

Lombard, M. (2014). Constructing ordinary places: Place-making in urban informal settlements in Mexico. Progress in Planning, 94, 1-53. https://doi.org/10.1016/j.progress.2013.05.003

Massey, R. T. (2013). Competing rationalities and informal settlement upgrading in Cape Town, South Africa: a recipe for failure. Journal of Housing and the Built Environment, 28(4), 605-613. https://doi.org/10.1007/s10901-013-9346-5 
McHarg, I. (2000). Proyectar con la naturaleza (2a. edición). Barcelona: Editorial GG.

Ministerio del Interior de Chile. (2014). Plan de inversiones reconstrucción y rehabilitación urbana, Valparaíso 2014 . Recuperado de http://www.interior.gob.cl/media/2014/09/PLAN-DE-INVERSION-VALPO2014-2021.pdf

Ministerio de Vivienda y Urbanismo, Minvu. (1999). Mecanismos para hacer ciudad: Seminario Internacional. Santiago: Minvu.

Ministerio de Vivienda y Urbanismo, Minvu. (2013). Mapa social de campamentos $2013 . \quad$ Recuperado de http://www.ministeriodesarrollosocial.gob.cl/btca/txtcompleto/mapasocial -campamentos.pdf

Moreira-Muñoz, A. y Borsdorf, A. (Ed.). (2014). Reserva de la biósfera en Chile. Laboratorios de Sustentabilidad. Santiago: Academia de Ciencias Austriaca y Pontificia Universidad Católica de Chile.

Muga, E. y Rivas, M. (2009). Mutaciones y cambios en la estructura urbana del Área Metropolitana de Valparaíso. En R. Hidalgo, C. De Mattos y F. Arenas (Ed.), Del país y urbano al país metropolitano (201-221). Santiago: Pontificia Universidad Católica de Chile.

Murtinho-Braga, F. (2007). Las quebradas de Valparaíso como cuencas urbanas. En M. Carmona, A. Falú, y E. Muga, Bordes e intersticios urbanos. Córdoba: Editorial Infinito.

Nogué, J. y Sala, P. (2006). Prototipo de catálogo de paisaje. Olot: Observatori del Paisatge.

Norberg-Schulz, C. (1979). Genius loci: paisaje, ambiente y arquitectura. Milán: Electa.

Organización de las Naciones Unidas para la Educación, la Ciencia y la Cultura, Unesco. (2014). Informe de misión de asesoramiento para el Sitio de Patrimonio Mundial Área Histórica de Ciudad-Puerto de Valparaíso. Recuperado de http://www.valparaisopatrimonio.cl/index.php/noticias/173-informeunesco-sobre-patrimonio-de-valparaiso

Pino, A. (2015). Quebradas de Valparaíso: memoria social autoconstruida. Santiago: Editorial Gráfica LOM y C.N.C.A. 
Plataforma Urbana. (2016). Valparaíso H30: Propuesta para aminorar factores de riesgo (incendio) y estimular la restauración ecológica. Recuperado de http://www.plataformaurbana.cl/archive/2015/03/31/valparaiso-h30propuesta-para-aminorar-factores-de-riesgo-incendio-y-estimular-larestauracion-ecologica/

Revi, A., Satterthwaite, D., Aragón-Durand, F., Corfee-Morlot, J., Kiunsi, R. B., Pelling, M., ... \& Sverdlik, A. (2014). Towards transformative adaptation in cities: the IPCC's fifth assessment. Environment and Urbanization, 26(1), 11-28. https://doi.org/10.1177/0956247814523539

Rogers, R. (2000). Ciudades para un pequeño planeta. Editorial Gustavo Gili, S.A.

Simon, D., Arfvidsson, H., Anand, G., Bazaz, A., Fenna, G., Foster, K., ... Wright, C. (2016). Developing and testing the Urban Sustainable Development Goal's targets and indicators-a five-city study. Environment and Urbanization, 28(1), 49-63. https://doi.org/10.1177/0956247815619865

Sojas, E. (2000). Postmetropolis: Critical studies of cities and regions. Los Angeles: Blackwell Publishing.

Tjallingii, S. (2007). Del cinturón verde a la estructura verde. En M. Carmona, A. Falú, y E. Muga, Bordes e intersticios urbanos $(\mathrm{xx}-\mathrm{xX})$. Córdoba: Editorial Infinito.

Unión Internacional para la Conservación de la Naturaleza, UICN. (2015). Recuperado de http://www.iucn.org/es/

Varley, A. (2013). Postcolonialising informality? Environment and Planning D: Society and Space, 31(1), 4-22. https://doi.org/10.1068/d14410 